\title{
Effects of Injection Pressure and Nozzle Diameter on Flame Structure of Diesel Spray of Agriculture Machine
}

\author{
Muataz Mohammed Ali Razzaq* and Azwan Sapit \\ Faculty of Mechanical and Manufacturing Engineering \\ Universiti Tun Hussein Onn Malaysia, 86400 Parit Raja, Malaysia; hd170052@siswa.uthm.edu.my
}

\begin{abstract}
Due to the mixing process of fuel and air in diesel engine, various diesel spray devices have been developed. More than one hundred years of development have made these diesel engines controllable and efficient, resulting in cleaner performance and enhanced fuel consumption. Still series of features: engine geometries, fuels, chemical-kinetics, in-cylinder flow, combustion process, sprays and fuel-air mixture formation must be investigating to reduce engine emissions, and increase performance of the engine. Alteration in fuel droplet and fuel-air mixture is one of the advanced elucidations in diesel engine. The injection pressure, ambient temperature and nozzle diameter can alter the fuel droplet and flame during combustion. The effects of injection pressure and nozzle hole diameter on flame structure and of impinging diesel spray were investigated. CFD software ANSYS IC Engine (Fluent) V-18 was employed to investigate such effects. For the injector nozzle having $0.18 \mathrm{~mm}$ diameter, injection pressure (140 MPa) with ambiet temperature $500{ }^{\circ} \mathrm{K}$ generates appreciably larger flame structure. Impinging spray flame of nozzle hole $0.1 \mathrm{~mm}$ shows much smaller size. The movement of the high velocity region was demonstrated to be at the injector tip in the beginning of injection period $\left(340^{\circ} \mathrm{CA}\right)$ which accompanied with the high pressure region. That satisfy the fact which is as spray cone be larger, the spray generates more and more swirl dominant flow that lead to higher evaporation rate. Furthermore, the maximum velocity of injection under $70 \mathrm{MPa}$ was decreased by $15.1093 \%$ than its value under $140 \mathrm{MPa}$. That satisfies the physical concept of pressure to velocity relation for compressible flow. Also, the maximum velocity of flow field with $0.1 \mathrm{~mm}$, injector diameter, was decreased by $26.5425 \%$ than its value in the case of $0.18 \mathrm{~mm}$ diameter.
\end{abstract}

Keywords: Agriculture Diesel Spray Machine, Combustion Chamber, Flame Structure, Injection Pressure, Nozzle Diameter, Velocity Contours

\section{Introduction}

The combustion and emission attributes are significantly impacted by spray atomization and fuel-air mixing processes in the combustion chamber of a diesel engine. Injection pressure and nozzle hole size are two imperative injection factors and affect the fuel-air mixing, spray atomization, combustion and emissions characteristics. High injection pressure is considered as an efficient technique to increase performance of Direct Ignition (DI) diesel engine performance and reduce emission on account of enriched fuel-air mixing and spray atomization features $^{1-4}$. Additionally, nozzle hole diameter also has a high impact on air entrainment amount, combustion and soot formation developments. Decreasing the injector nozzle hole size can provide the effective betterments in combustion and emissions in diesel engine ${ }^{6,7}$. Many studies were carried to investigate the effects of reduced nozzle diameter and increased injection pressure on combustion and emissions in DI engine ${ }^{8-12}$, many of these studies concentrated on improvements in performance and combustion process and reduction in emissions in diesel engines. In the meantime, authors mainly scope in their studies to the normal injection pressure and conventional nozzle size.

The development of high-pressure-injection innovation outcome in adequate atomization and accommodate 
for improved air-fuel mixture ${ }^{13-16}$. All these researchers showed importance for the better performance on account of the injector parameters and concluded them as key tools for engine performance enhancement. Zhang et al. ${ }^{2}$ investigated the mixture formation progression of flat wall impinging spray under under ultra-high injection pressure $($ Pinj $=300 \mathrm{MPa})$ along with micro-hole nozzle $(\mathrm{d}=0.08 \mathrm{~mm})$. In his investigation, soot formation attributes of impinging spray flame were also matched with conventional $(0.16 \mathrm{~mm})$ and micro-hole $(0.08 \mathrm{~mm})$ nozzle free spray flame. The result revealed that the combination of ultra-high injection pressure and micro-hole nozzle is significant to achieve fast vaporization and high air entrainment amount. It is sensible to guess that ultrahigh injection pressure and micro-hole nozzle would be advantageous for soot decrement. Conclusively, nozzle hole diameter and injection pressure is important to investigated the effect on flame structure and soot formation of flat wall impinging spray on combustion and other characteristics. Also, to produce an optimized type of nozzle, it needs to comprehend the impact of fuel spray with different pressures and ambient temperatures. The aim of this study is to provide information on the effects of various nozzle diameters will be studied. The ambient conditions effect on the chamber thermodynamic performance which governs the combustion process.

\section{Material and Method}

The effects of injection pressure (Pinj $=70 \mathrm{MPa} \& 140$ $\mathrm{MPa})$, and nozzle hole diameter $(\mathrm{d}=0.1 \mathrm{~mm}$ and 0.18 $\mathrm{mm}$ ) on flame structure and of impinging diesel spray were investigated. This study has been conducted by employing the CFD software ANSYS IC Engine (Fluent) $\mathrm{V}-18$. The numerical approach was the viscous flow with the Discrete-phase model and species transport equation for modeling the injection process. The solution algorithm was the PISO algorithm. The simulations included turbulence by utilizing the standard $\mathrm{k}$-epsilon model. The spatial discretization schemes used in this study was second order upwind for the momentum, energy, turbulent kinetic and species equations and the first order upwind for the turbulent dissipation equation.

\subsection{Decomposition and Meshing}

Meshing process has two different approaches in order to proceed for analyzing engine combustion problem, a hybrid approach for Spark Ignition (SI) engine, while, the second is layering process used for the vertical valves CI engine. Layering Process was used in this research. Meanwhile, the meshing process used in this study is consisting of the following sequence stages:

1. Geometry decomposed into the numerous parts and meshing proceeds individually.

2. Different meshing methods signed for decomposed geometry in the different zones.

3. Inserting the case file within the CFD system merged into the journal file.

4. The final stage represented by transient in-cylinder simulation.

Structural meshing method approached was applied for in-cylinder engine body as combustion chamber while tetrahedral meshing method was utilized for the bowl piston. Meshing coincides to the piston moving through and swing between top and Bottom Dead Centers (BDC), also moving mesh cause to generate a huge mesh volume density. ANSYS FLUENT v18.0 is used to simulate the engine model and is meshed by virtual topology. A multi-block strategy is broken to fragment the calculation domain into two main regions; chamber and piston layer, the mesh shown in Figure 1. Both zones were meshed with hexahedron cells (structured mesh) and layered by several commands.

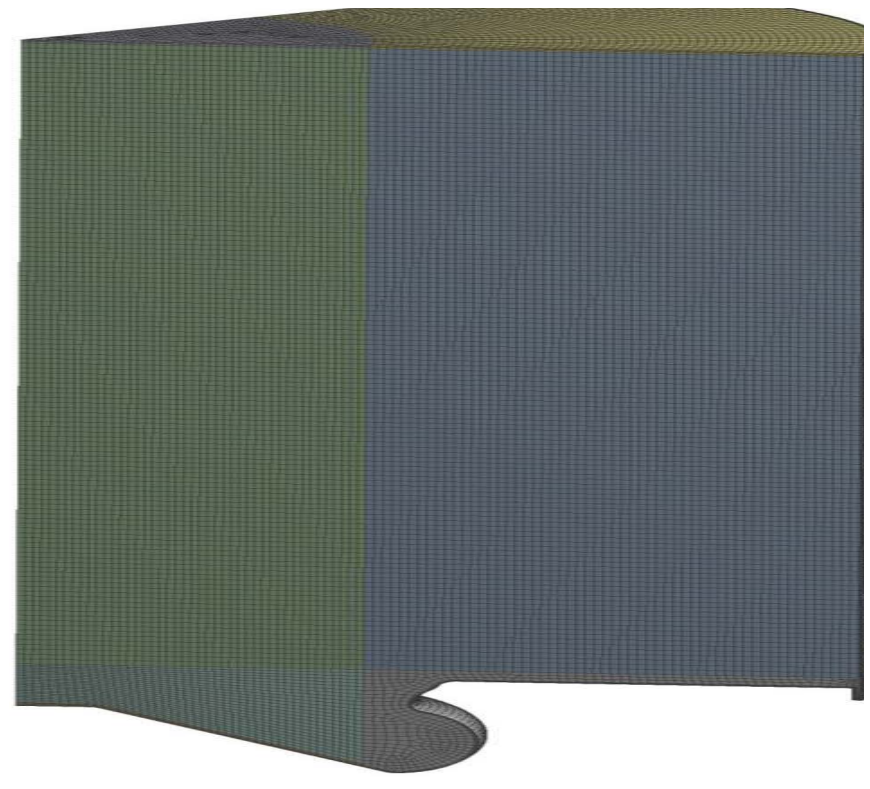

Figure 1. Three-dimensional engine sector grid. 
Table 1. Mesh summery for the computational domain

\begin{tabular}{|l|l|}
\hline Description & Quantity \\
\hline Total Nodes & 527196 \\
\hline Total Elements & 504202 \\
\hline Total Body Elements & 504202 \\
\hline
\end{tabular}

\begin{tabular}{|l|l|l|}
\hline Body Name & Nodes & Elements \\
\hline Piston Outer & 38808 & 33661 \\
\hline Piston Inner & 26595 & 23946 \\
\hline Piston Inflation & 4925 & 3684 \\
\hline Chamber Inner Bottom & 127065 & 117888 \\
\hline Chamber Outer Bottom & 330498 & 314880 \\
\hline Chamber Inner Top & 330498 & 314880 \\
\hline Chamber Outer Top & 3940 & 2760 \\
\hline
\end{tabular}

\begin{tabular}{|l|l|l|l|l|}
\hline $\begin{array}{l}\text { Generic } \\
\text { Element } \\
\text { Type Name }\end{array}$ & $\begin{array}{l}\text { Mechanical } \\
\text { ADPL } \\
\text { Name }\end{array}$ & $\begin{array}{l}\text { NASTRAN } \\
\text { Name }\end{array}$ & $\begin{array}{l}\text { ABAQUS } \\
\text { Name }\end{array}$ & $\begin{array}{l}\text { STL } \\
\text { Name }\end{array}$ \\
\hline $\begin{array}{l}\text { Linear } \\
\text { Hexahedron }\end{array}$ & Mesh 200 & CHEXA & C3D8 & N/A \\
\hline $\begin{array}{l}\text { Linear } \\
\text { Wedge }\end{array}$ & Mesh 200 & CPENTA & C3D6 & N/A \\
\hline
\end{tabular}

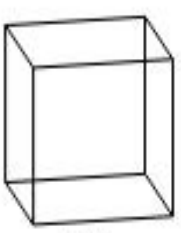

0.0

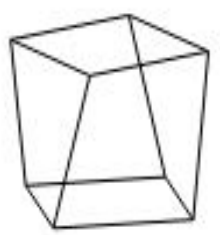

approximately 0.2

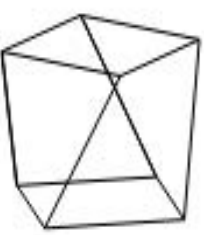

approximately 0.4
Figure 2. Warping factor for hexahedrons.

Sweep, face sizing, and edge sizing and inflation commands used to produce a high quality mesh for each zone. The final mesh consisted of 504202 elements with 527 196 hexahedron cells. A three inflation layers was set to be located in next to wall boundaries in the domain. Such are useful if using turbulence model because of its ability to resolve the viscous boundary layer due to laid a majority of small blocks near to the wall.

\subsection{Mesh Metric}

To insure that there is enough cells in the computational domain without spending a lot of cells to simulate the flow far from the nozzle. The mesh metrics were investigated to obtain the grid quality.

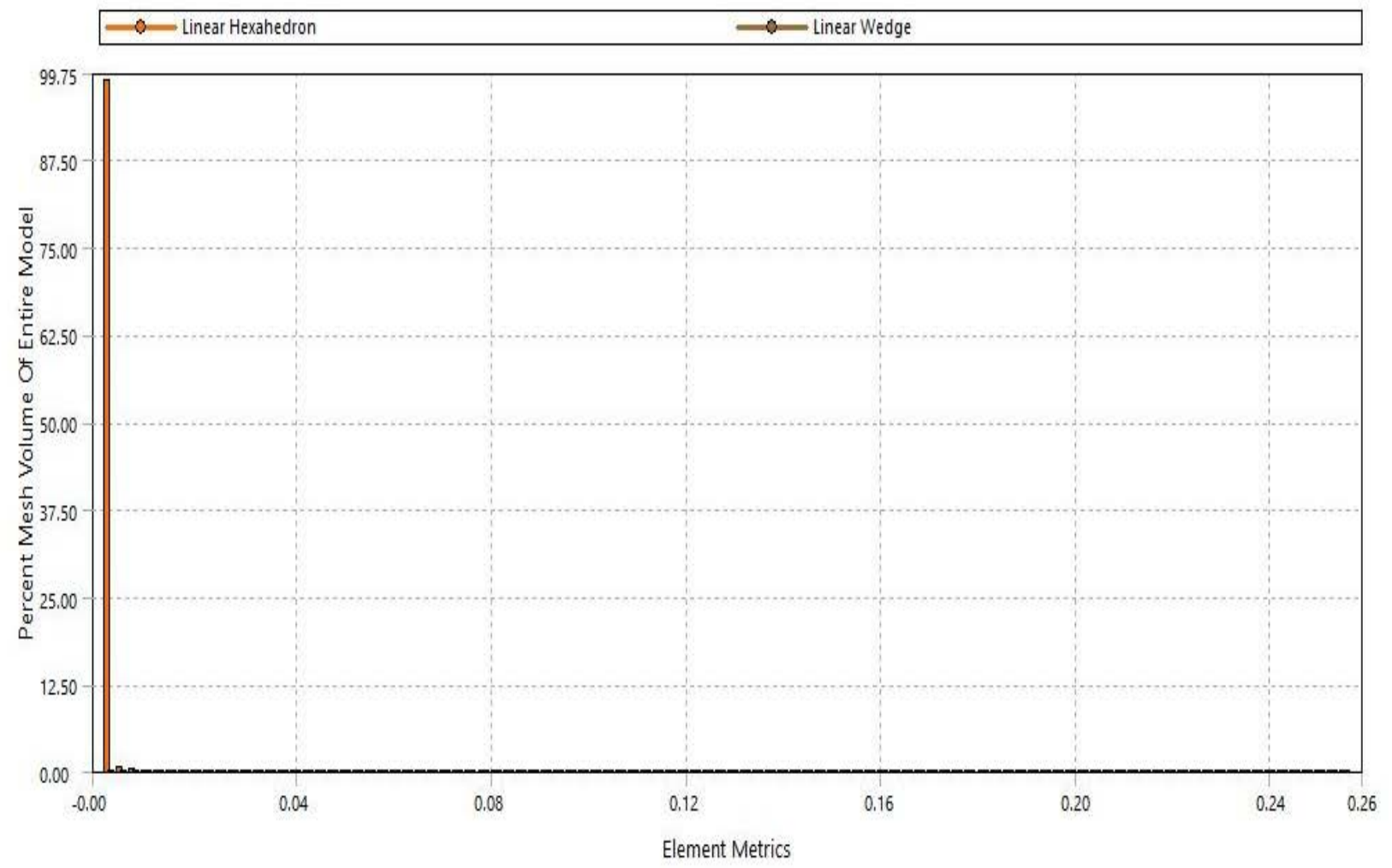

Figure 3. Mesh metric, warping factor plot. 
Warping factor is one of the mesh metric which computed and tested for hexahedron elements and the quadrilateral face. A high factor may designate a situation the underlying element formulation can't grip sound.

The warping factor for the cells factor and calculated for all the 6 quadrilateral faces of a hexahedron. Any hexahedron cell having all flat faces will have a zero warping factor (Figure 2: Warping Factor for hexahedrons).

The mesh generated for this study shown superior results for warping factor where $99.75 \%$ (as in Figure 3) from the entire model elements have 0 warping which guaranteed that the elements not deformed in any way and the convergence will be smooth.

The other primary factor to measure the quality of a mesh is Skewness. It defines how mesh generated is near to ideal cell. That it, highly skewed faces and cells are unacceptable because the governing equations being solved assume that the cells are relatively equiangular.

The following Table 2 lists the range of skewness values and the corresponding cell quality ${ }^{17}$.

According to Table 2, "0" value designates an equilateral cell (best) while "1" value designates totally degenerate cell (worst). Degenerate cells (slivers) are categorized by nodes that are nearly coplanar

Also, the generated mesh for this study shown excellent results for skewness where $42.7 \%$ (as in Figure 4)
Table 2. Skewness values evaluating

\begin{tabular}{|l|l|}
\hline Value of Skewness & Cell Quality \\
\hline 1 & Degenerate \\
\hline $0.9-1$ & Bad (sliver) \\
\hline $0.75-0.9$ & Poor \\
\hline $0.5-0.75$ & Fair \\
\hline $0.25-0.5$ & Good \\
\hline $0-0.25$ & Excellent \\
\hline 0 & Equilateral \\
\hline
\end{tabular}

from the entire model elements have 0 skewness and $57 \%$ have skewness lower than 0.1 .

\section{Experimental Research of 4135ACa Four-Stroke Medium Speed Engine}

In this thesis a $4135 \mathrm{ACa}$ four-stroke medium speed engine was used for the validation and simulations. All the investigations were conducted for the same engine specifications that listed in Table 3 . The engine is equipped with a direct injection, 4135ACa engines are manufactured as in-line with four cylinder configurations.



Figure 4. Mesh metric, skewness plot. 
The $4135 \mathrm{ACa}$ engine is running with a speed of 1500 rounds per minute and produced an output power of $66.2 \mathrm{~kW}$ per cylinder. The engine bore is $135 \mathrm{~mm}$ and the stroke $150 \mathrm{~mm}$.

Tan et al. $^{18}$ investigated experimentally the performance of the engine "4135ACa," which is a brand of Dongfeng, and reported a set of results. The results were suggested that the burning efficiency could be increased with the increase of $\mathrm{O}_{2}$. When it reached $60 \%$, the output heat in the cylinder has been equal to that under the operation condition of air intake.

However, this thesis, as defined previously, was focused on nozzle diameter effect with different ambient and inlet rounding conditions on combustion process characteristics. The results were validated to the results of $\operatorname{Tan}^{18}$ and the engine specification would be taken as it is.

\section{Boundary Conditions}

All wall boundaries containing the moving boundaries such as piston, cylinder and valves were retained at constant temperatures during the simulation. Where the top sector face (involving valves) at $580 \mathrm{~K}$, piston walls at 660 $\mathrm{K}$ and cylinder walls at $540 \mathrm{~K}$. One of valves in the positive Y-direction was assigned as inlet port and the other side as exhaust port. A two different ignition pressures, $70 \mathrm{MPa}$ and $140 \mathrm{MPa}$, were applied. Temperature of the ambient was investigated for $500{ }^{\circ} \mathrm{K}, 800{ }^{\circ} \mathrm{K}$ and $900{ }^{\circ} \mathrm{K}$. The flow direction at the inlet is set parallel to the intake runner walls. The internal interfaces between chamber and valve zones did not contribute physically in the calculation; however, when the valves are fully closed, the

\begin{tabular}{|l|l|}
\hline Table 3. Specifications of 4135ACa Engine \\
\hline Engine & Main Parameter \\
\hline Engine Type & Inline 4-Cylinder \\
\hline Bore and Stroke & 4 -Stroke Water Cooled \\
\hline Capacity & $135 \mathrm{~mm} / 150 \mathrm{~mm}$ \\
\hline Compression Ratio & $8.85 \mathrm{~L}$ \\
\hline Rated Power & $66.2 \mathrm{~kW} / 1500 \mathrm{rpm}$ \\
\hline Injection Timing & $20^{\circ}$ before TDC / 48 \\
\hline Inlet Valve Open / Close Timing & After BDC \\
\hline Outlet Valve & $48^{\circ}$ before BDC / $20^{\circ}$ \\
\hline Open / Close Timing & After TDC \\
\hline Shape of Combustion Chamber & $\omega$ shape \\
\hline Intake Air Type & Naturally Aspirated \\
\hline
\end{tabular}

interfaces are treated as walls and the boundary conditions are determined from the adjacent wall boundaries. These conditions were applied for two nozzle diameters (0.1 and $0.18 \mathrm{~mm}$ ).

The diesel fuel which was utilized in this simulation is n-heptane (C7H16) with properties taken according to the experimental data listed in Table 4. Four injection points are set at the center of the cylinder head, Nozzle geometry and injection conditions are summarized in Table 5.

\section{In-cylinder Flow Validation and investigation}

The in-cylinder flow validation has been done with standard $\mathrm{k}-\varepsilon$ turbulence model for mean in-cylinder pressure. Due to the specified geometry of the 4135CAc diesel engine used in this study, limited experimental data is available for validation. Therefore, the mean in-cylinder pressure of the model in this study was compared with the experimental data used by Tan et al. ${ }^{18}$.

The simulated results of difference in the volumeaveraged in-cylinder pressure obtained from ANSYS IC and Diesel RK compared with the experimentally results observed by Tan for nozzle diameter of $(0.224 \mathrm{~mm})$ and engine speed of $(1500 \mathrm{rpm})$ was shown in Figure 5.

The results obtained by ANSYS and Diesel RK have divergence of $9.83607 \%$ and $5.71429 \%$ respectively than experimental data. However, these differences occur

Table 4. Diesel fuel properties

\begin{tabular}{|l|l|}
\hline Fuel type & n-heptane (C7H16) \\
\hline Thermal Conductivity & $0.149 \mathrm{~W} / \mathrm{m}-\mathrm{k}$ \\
\hline viscosity & $0.0024 \mathrm{~kg} / \mathrm{m}-\mathrm{s}$ \\
\hline Vapor Molecular Weight & $100.204 \mathrm{~kg} / \mathrm{kmol}$ \\
\hline Specific Heat & $2090 \mathrm{j} / \mathrm{kg}-\mathrm{K}$ \\
\hline Density & $840 \mathrm{~kg} / \mathrm{m} 3$ \\
\hline Latent Heat & $277000 \mathrm{j} / \mathrm{kg}$ \\
\hline
\end{tabular}

Table 5. Nozzle configurations and spray injection parameters

\begin{tabular}{|l|l|}
\hline Number of holes & 4 \\
\hline Hole diameter & $0.1,0.18 \mathrm{~mm}$ \\
\hline Angle of fuel-jet axis & $70^{\circ}$ \\
\hline Start of injection & $100.204 \mathrm{~kg} / \mathrm{kmol}$ \\
\hline Injection timing & $18^{\circ}$ before TDC \\
\hline
\end{tabular}




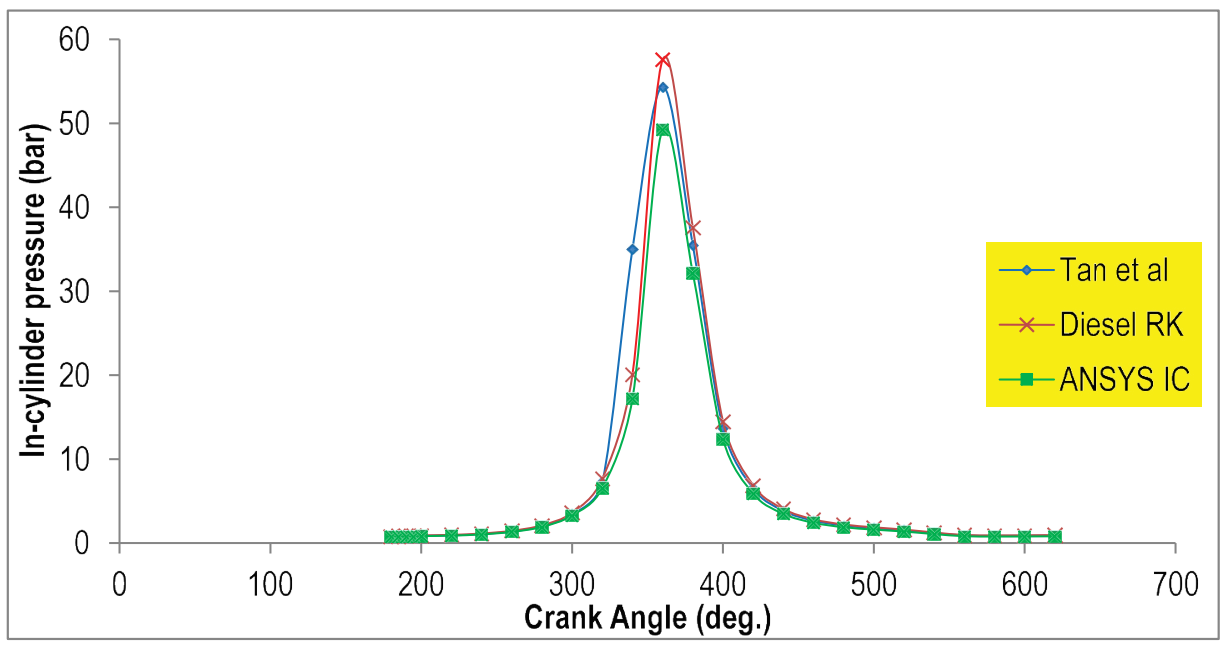

Figure 5. The validation for simulation models of the 4135ACa engine.

because the dimensions of the combustion chamber are guessed and not actual. In addition, the standard k- $\varepsilon$ turbulence model was contains an error percentage which differ from model to another. Also, the numerical solution itself has a residual value which represents in some kind the divergence.

In general, the results of validation did not contain a large divergence and the results with less than $10 \%$ were could be considered as acceptable and allowable to dealing with.

However, this engine was simulated and analyzed for an operational speed of $1500 \mathrm{rpm}$ to investigate engine performance. For our standard case of nozzle diameter of $(0.1 \mathrm{~mm})$ and ambient temperature of $500 \mathrm{~K}$, the volumeaveraged in-cylinder pressures were shown in Figure 5.
The peak pressure for simulated case was found to be 48.6 bar. The flow pressure structures at the beginning of fuel injection with different crank angles. Figure 6 presents the pressure contours on a $60^{\circ}$ sector of in-cylinder chamber (combustion chamber).

\section{Result}

\section{1 The In-Cylinder Pressure Contours with Different Crank Angles}

From Figure 7, the contours illustrated how the area of injection or the cylinder core region represents the area of higher pressure due to the effects of flow characteristics which conclude swirl flow and vortices generation.

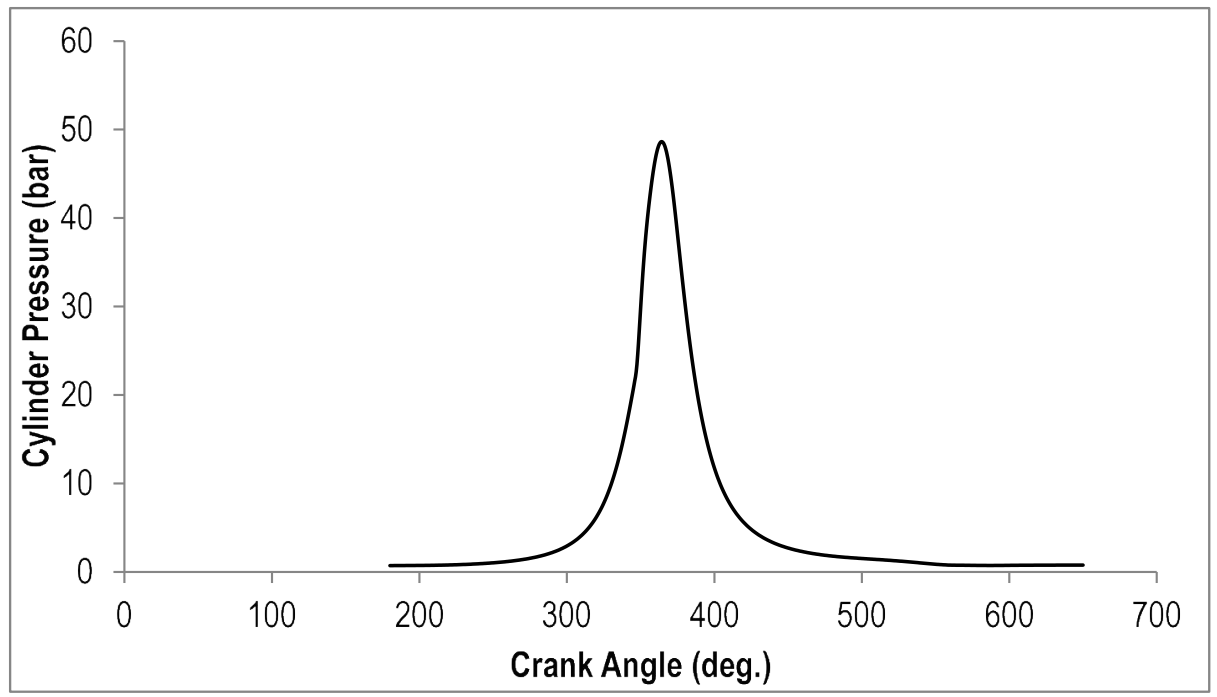

Figure 6. The in-cylinder pressure of the 4135ACa engine. 

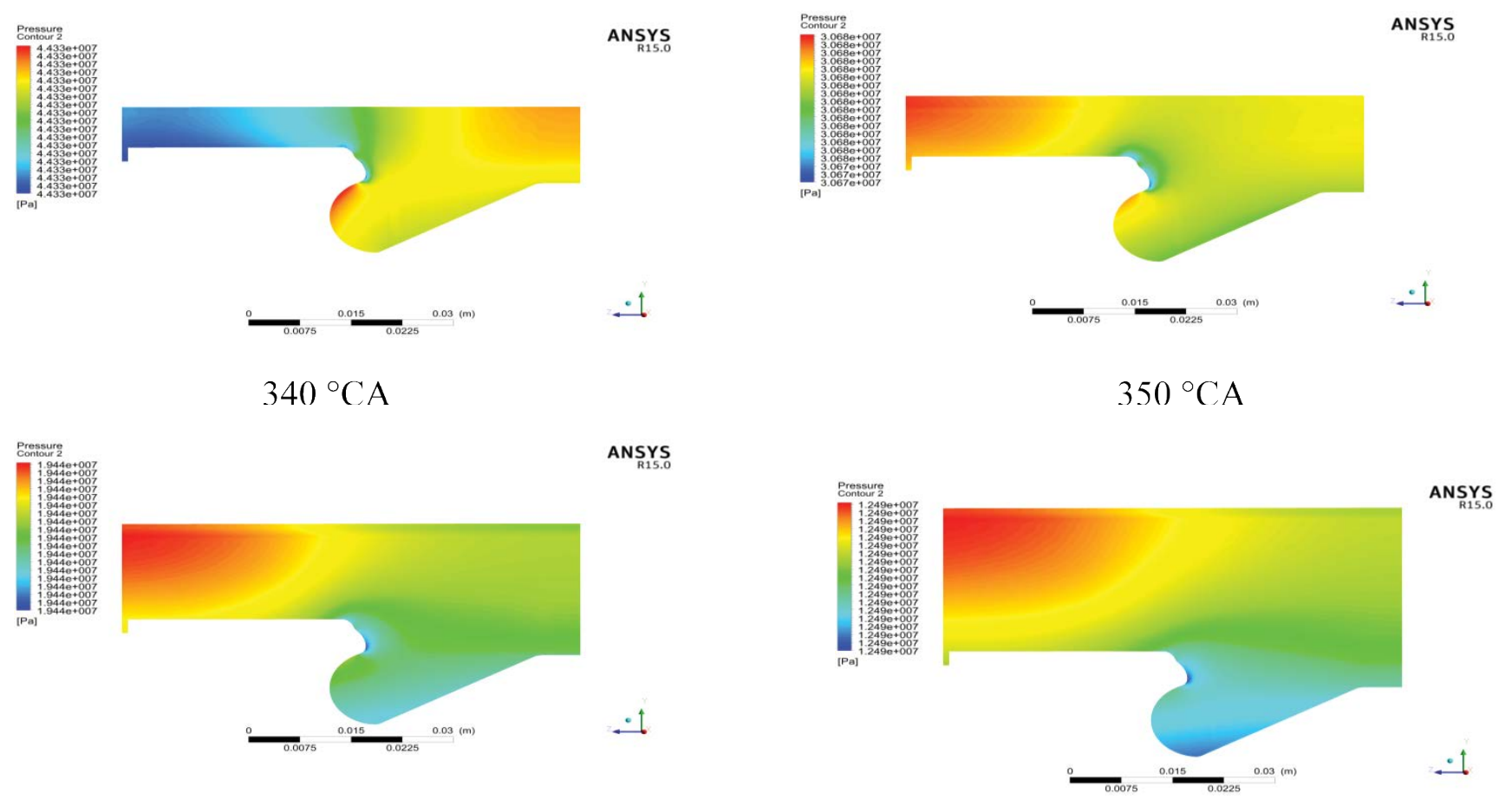

$\underset{\substack{\text { ANSYSS } \\ \text { R15.0 }}}{ }$

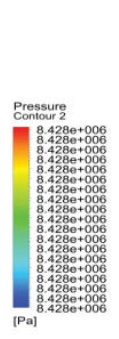

$360{ }^{\circ} \mathrm{CA}$
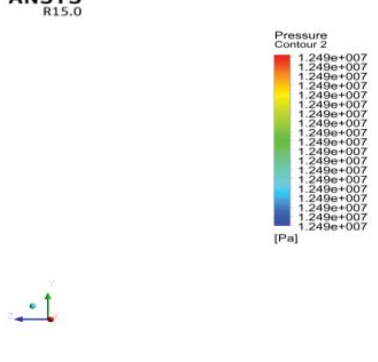

$370{ }^{\circ} \mathrm{CA}$
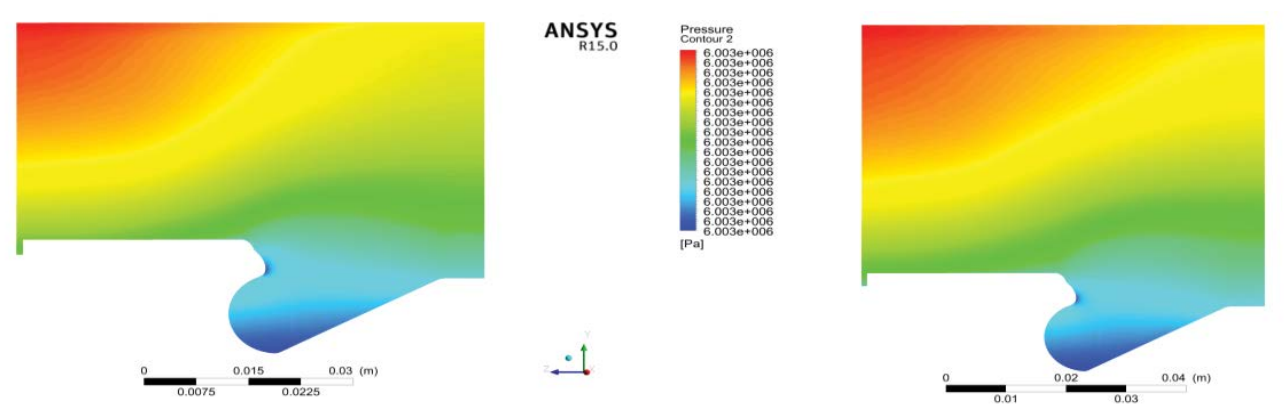

ANSYS
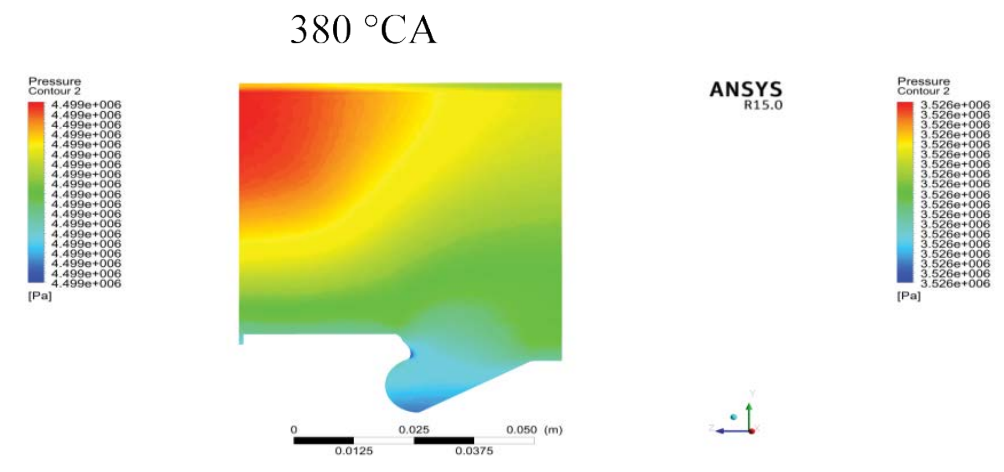

$400{ }^{\circ} \mathrm{CA}$
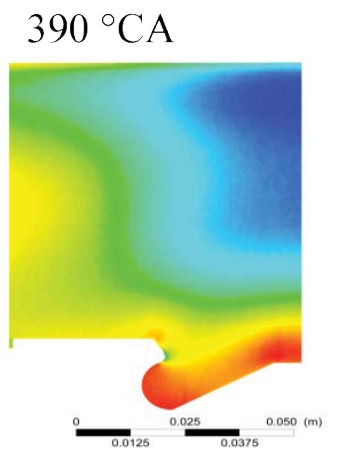

ANSYS

$410^{\circ} \mathrm{CA}$

Figure 7. The in-cylinder pressure contours with different Crank Angles (CA). 
It clearly shows that the pressure of injection particles volume is much higher than the vapor pressure. In fact, those due to the formation of vortex which indicate pressure levels much higher than the vapor pressure of the liquid diesel. The region of higher pressure will be transmitted to the cylinder boundary region due to flow characteristics and fuel penetration. Also, the in-cylinder pressure increases the crank angle increasing and reaching after TDC. Aimed at the injection pressure effect, a greater injection pressure results a longer flame length. In the meantime, flame length increases more quickly and reaches quasi-steady length former for great injection pressure. The development of quasi-steady stage for great injection pressure shows an improvement of soot oxidation.

\section{2 Velocity Vectors and Contours}

In the CFD representation for variable values, the common way to explain distributions of parameters is by plotting contours. Contours are a visual appearance for various values in a colored way. Each color refers to a range of magnitudes which explained within an attached legend. In this section, contours, vectors and $\mathrm{XY}$ plots used to explain the results.

\subsubsection{Velocity Vectors within the Combustion Chamber}

The flow structure evaluated by numerical analysis was examined. For the flow structure, Figure 8 captures the velocity vectors on a cut plane through the middle of the section port (YZ plane) at the combustion chamber which present $60^{\circ}$ sector (from the whole $360^{\circ}$ combustion chamber) with different crank angle CA.

The combustion sector was simulated at a speed of $1500 \mathrm{rpm}$ for valve timings $\left(340-390^{\circ} \mathrm{CA}\right.$ ) (include injection period). The cylinder head wall between intake and exhaust valve was smooth. The simulation results were operated at specified conditions which are; ambient temperature of $500 \mathrm{k}$, injection pressure of $70 \mathrm{MPa}$ and nozzle diameter of $0.1 \mathrm{~mm}$.

At every $10^{\circ}$ of Crank Angle (CA) step, the velocity vector plot observes the transient behavior of the flow. A series of vector fields for the solution are presented in Figure 8. From the figure, it is clear that the vortex core is moving from side to side inside the chamber volume. The movement of the high velocity region was demonstrated to be at the injector tip in the beginning of injection period $\left(340^{\circ} \mathrm{CA}\right)$ which accompanied with the high pressure region as shown in Figure 7. In this part, the vortex was generated in the boundary region and the core region has no secondary motion. In fact, that conclusion satisfies the known behavior of vortices where its core present low pressure regions. However, a large recirculation zone inside the chamber volume which occur in the core region (after injection) and piston curvatures which came with secondary (swirl) flow generation. This swirl flow has a high advantageous effect on fuel drops evaporation, mixing and combustion processes.

The velocity contours for the same case were shown in Figure 9 with particles flow demonstration by tracking plot. In this figure, the particle concentration region appears in velocity contour as moderate velocity region which its upstream flow presents high velocity (that due to secondary flow) and its downstream present low velocity regime. That satisfy the fact which is as spray cone be larger, the spray generates more and more swirl dominant flow that lead to higher evaporation rate.

\subsubsection{Velocity Field Variation with Different Injection Pressure}

From ideal gas law, the pressure variation has proportional effect on gas density $(\mathrm{P})$ where the density, at constant flow rate, effect inversely on velocity magnitude. This is a physical concept. Therefore, velocity field was investigated numerically within the combustion chamber to capture the effect of injection pressure on velocity distribution. The simulations have been done for two injection pressures (70Mpa and 140Mpa). Also, the simulation results were operated at specified conditions which are; ambient temperature of 500k and nozzle diameter of $0.1 \mathrm{~mm}$.

A velocity contours were presented in Figure 10. From the figure, the maximum velocity of injection under 70 MPa was decreased by $15.1093 \%$ than its value under 140 MPa. That satisfies the physical concept of pressure to velocity relation for compressible flow.

In fact, it's more complicated. The relation between velocity and pressure has effect on many parameters like swirl intensity, vorticity, turbulent kinetic energy, turbulence dissipation and more others. The in-cylinder flow, as shown in Figure 11, considered as one of the higher complexity flows. 


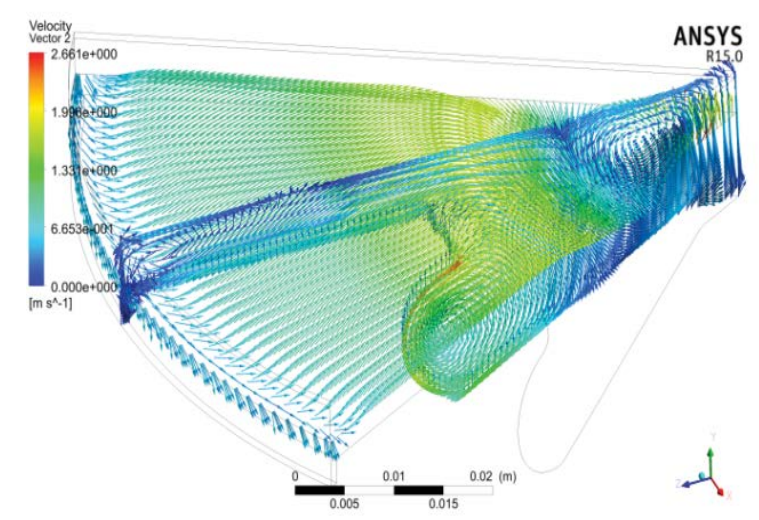

$340{ }^{\circ} \mathrm{CA}$

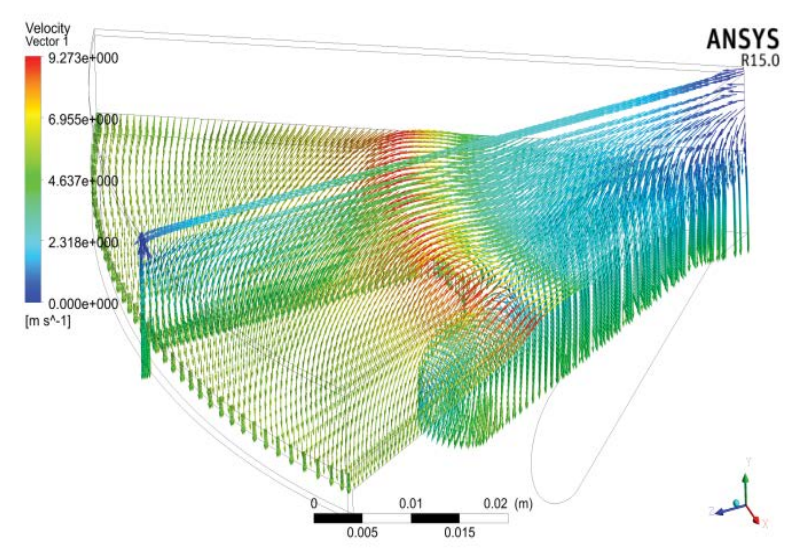

$360{ }^{\circ} \mathrm{CA}$
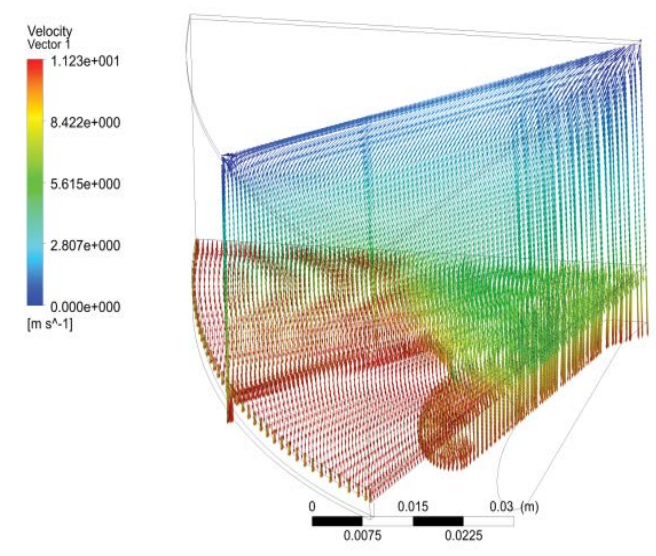

$380{ }^{\circ} \mathrm{CA}$

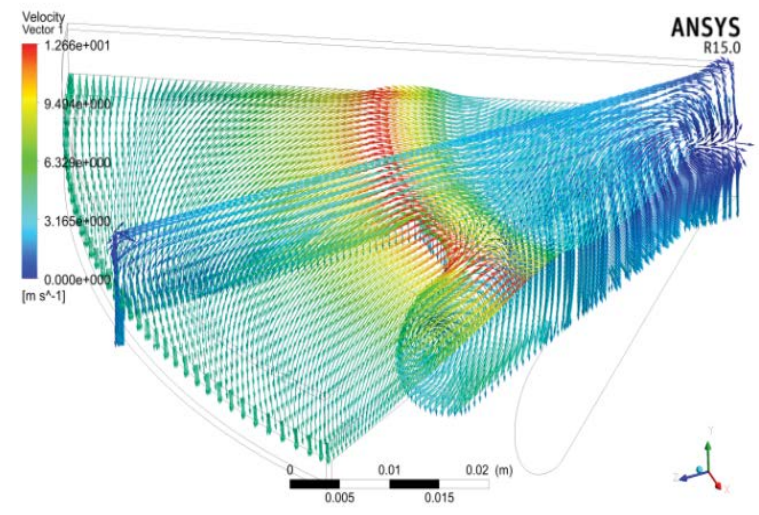

$350{ }^{\circ} \mathrm{CA}$

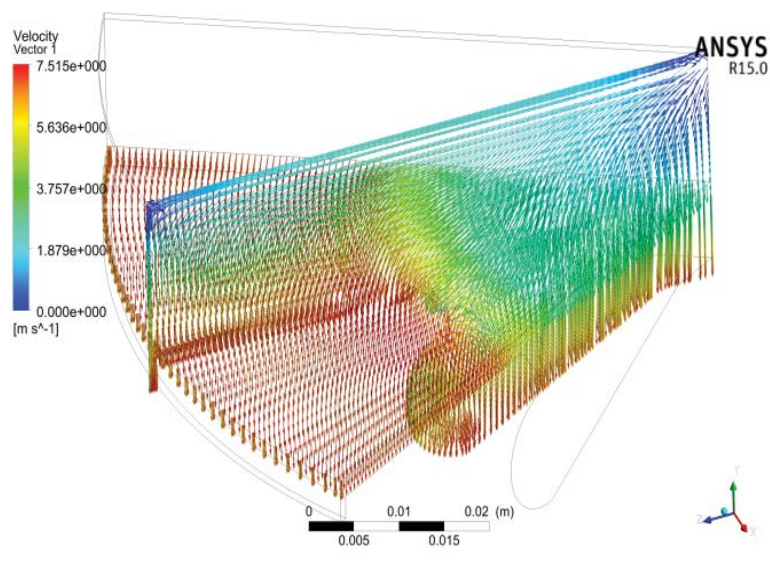

$370{ }^{\circ} \mathrm{CA}$
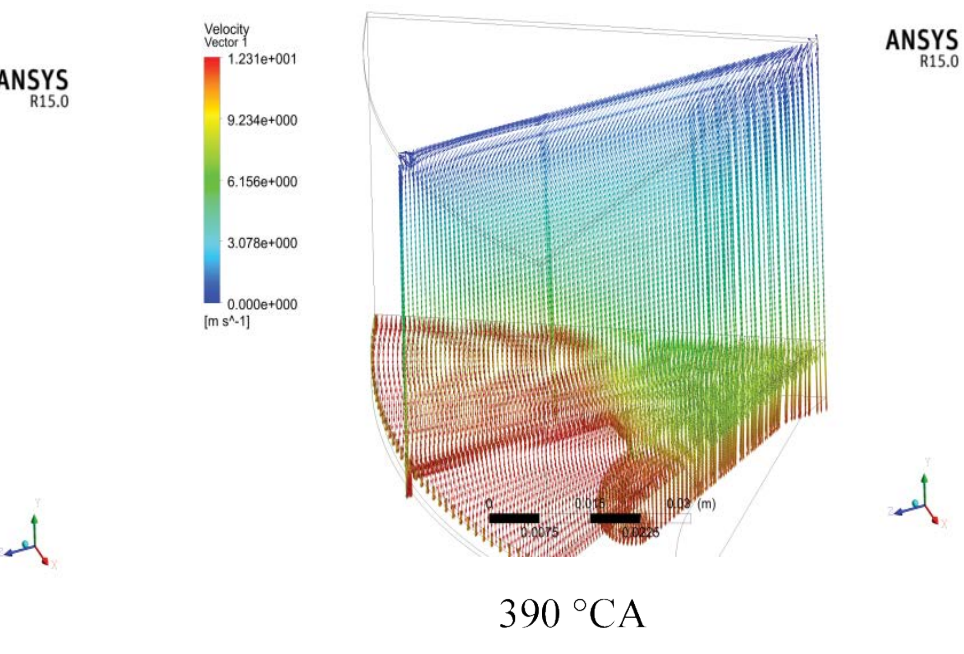

Figure 8. The in-cylinder velocity vectors with different Crank Angles (CA). 

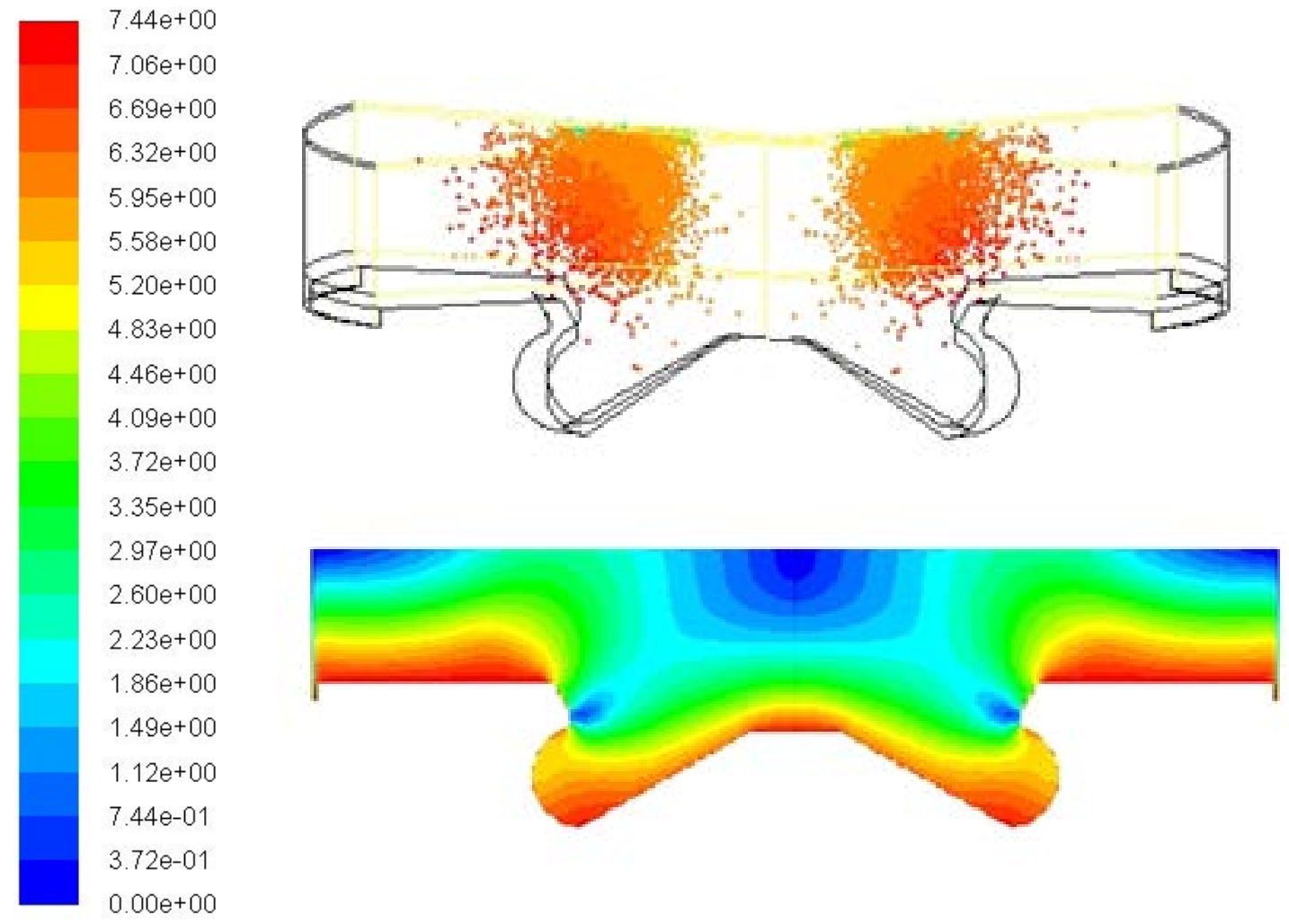

Figure 9. The combustion chamber velocity contours with particles tracking at $350^{\circ}$ Crank Angles (CA) $\left(10^{\circ}\right.$ after injection period end).
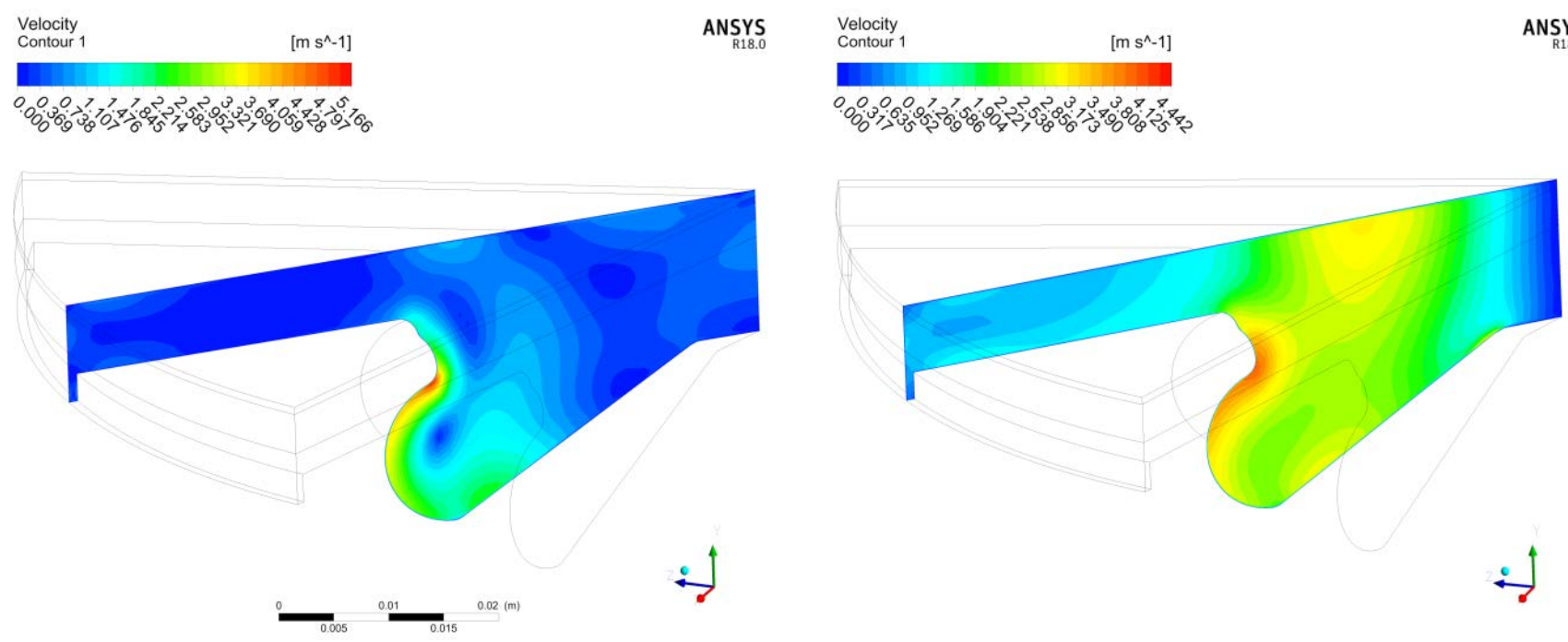

$70 \mathrm{MPa} 140 \mathrm{MPa}$

Figure 10. The velocity distribution within combustion chamber under different injection pressures. 


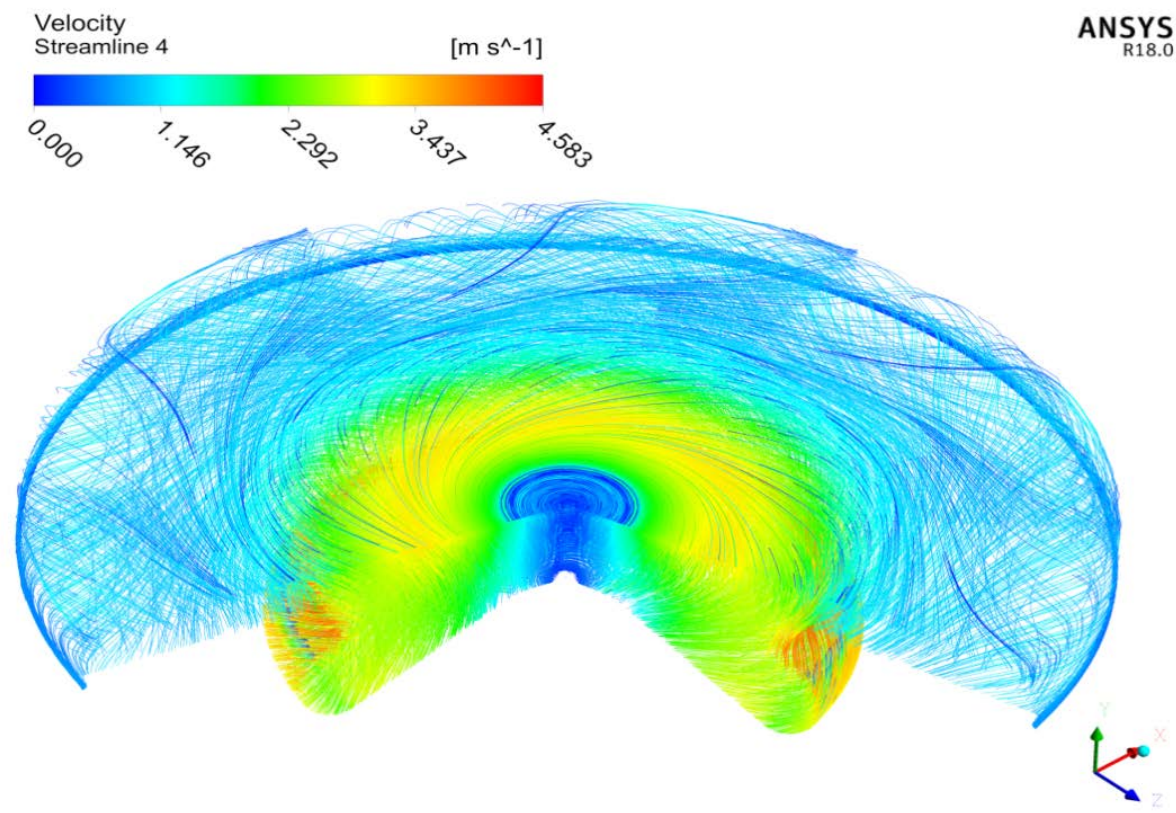

Figure 11. The flow stream line within combustion chamber under 140MPa injection pressure.

\section{Velocity Field Variation with Different Nozzle Diameters}

It's known that a larger diameter opening will always give more flow. Therefore, the mass flow rate proportional varies to nozzle diameter where the nozzle diameter effect inversely to velocity magnitudes. This is, also, a physical concept. Therefore, velocity field was investigated
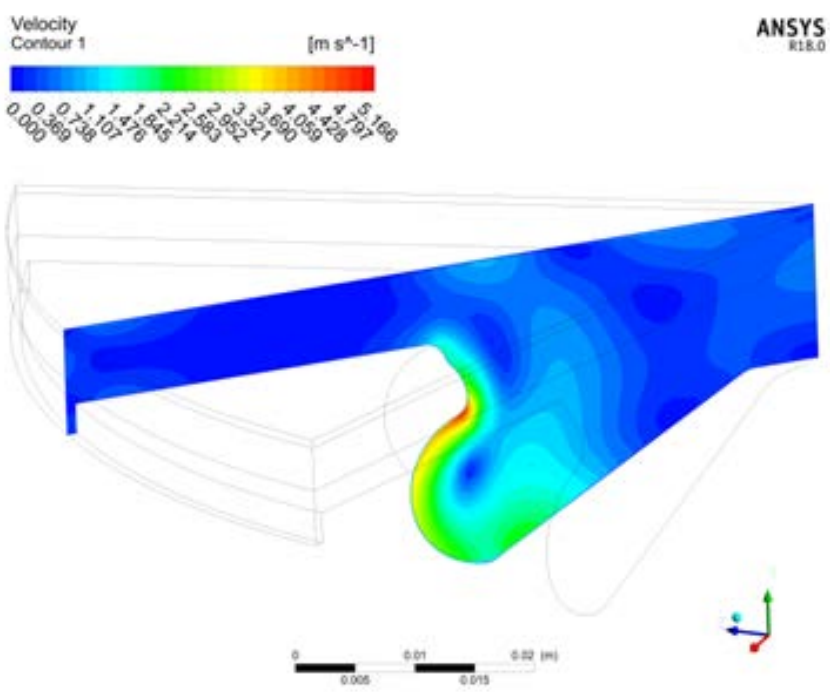

numerically within the combustion chamber to capture the effect of nozzle diameter on velocity distribution. The simulations have been done for injector diameters $(0.1$ $\mathrm{mm}$ and $0.18 \mathrm{~mm})$. Also, the simulation results were operated at specified conditions which are; ambient temperature of 500k under injection pressure of $70 \mathrm{MPa}$.

A velocity contours were presented in Figure 12 . From the figure, the maximum velocity of flow field with
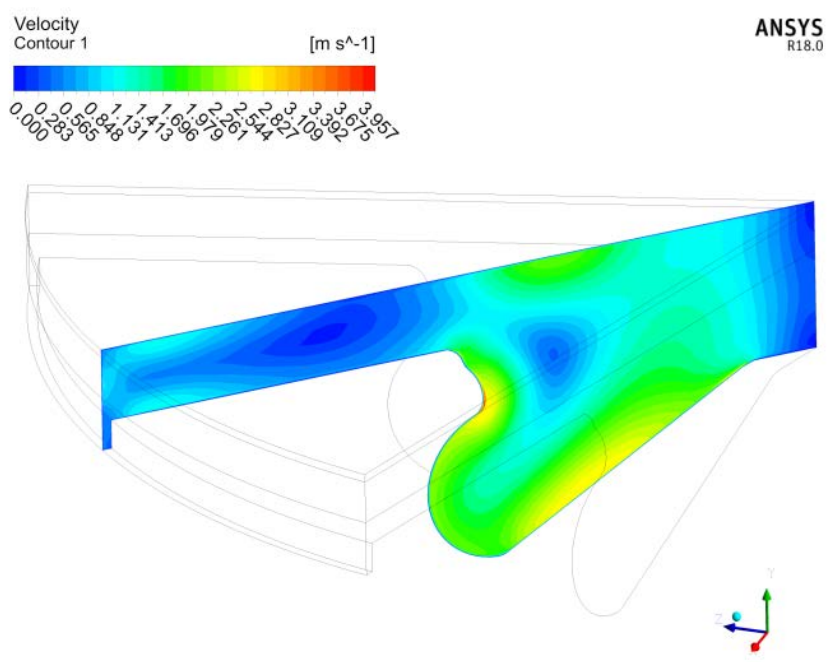

$70 \mathrm{MPa} 140 \mathrm{MPa}$

Figure 12. The velocity distribution within combustion chamber under different injector diameters. 
$0.1 \mathrm{~mm}$, injector diameter, was decreased by $26.5425 \%$ than its value in the case of $0.18 \mathrm{~mm}$ diameter.

\section{Conclusion}

Flame structure of impinging diesel spray were studied with high injection pressure and nozzle hole diameter in a combustion vessel with ANSYS IC Engine (FLUENT) V-18. The effects of injection pressure and nozzle hole diameter on velocity vectors and contours in combustion chamber along with different degree crank angle during the injection period were compared and discussed. The main conclusions are summarized as follow:

For the injector nozzle having $0.18 \mathrm{~mm}$ diameter, injection pressure $(140 \mathrm{MPa})$ with ambiet temperature $500{ }^{\circ} \mathrm{K}$ generates appreciably larger flame structure. Impinging spray flame of nozzle hole $0.1 \mathrm{~mm}$ shows much smaller size. The movement of the high velocity region was demonstrated to be at the injector tip in the beginning of injection period $\left(340^{\circ} \mathrm{CA}\right)$ which accompanied with the high pressure region. That satisfy the fact which is as spray cone be larger, the spray generates more and more swirl dominant flow that lead to higher evaporation rate. Furthermore, the maximum velocity of injection under $70 \mathrm{MPa}$ was decreased by $15.1093 \%$ than its value under $140 \mathrm{MPa}$. That satisfies the physical concept of pressure to velocity relation for compressible flow. Also, the maximum velocity of flow field with $0.1 \mathrm{~mm}$, injector diameter, was decreased by $26.5425 \%$ than its value in the case of $0.18 \mathrm{~mm}$ diameter.

\section{References}

1. Wang X, Huang Z, Zhang W, Kuti OA, Nishida K. Effects of ultra- high injection pressure and micro-hole nozzle on flame structure and soot formation of impinging diesel spray. Applied Energy. 2011; 88:1620-8. https://doi. org/10.1016/j.apenergy.2010.11.035

2. Zhang W, Nishida K, Gao J, Miura D. An experimental study on flat-wall impinging spray of micro hole nozzles under ultra-high injection pressures. Proceedings of the Institution of Mechanical Engineers, Part D: Journal of Automobile Engineering. 2008; 22:1731-41. https://doi.org/10.1243/09544070JAUTO858

3. Ali HA. Comparison fine spray nozzle for two phase flow within experimental and simulation, Master Thesis, Universiti Tun Hussein Onn Malaysia; 2015.
4. Pielecha I, Borowski P. Comparative analysis of fuel penetration and atomization with the use of two angularly arranged injectors in the rapid compression machine and constant volume chamber. ILASS Americas 26th Annual Conference on Liquid Atomization and Spray Systems, Portland, OR; 2014 May.

5. Andersen FH. Numerical simulation of the flow in fuel nozzles for two-stroke diesel engines, Master Thesis; 2011 Jul.

6. Wang X, Kuti OA, Zhang W, Nishida K, Huang Z. Effect of injection pressure on flame and soot characteristics of the biodiesel fuel spray. Combustion Science and Technology. 2010; 182:1369-90. https://doi. org/10.1080/00102201003789139

7. Wang X, Huang Z, Kuti OA, Zhang W, Nishida K. Experimental and analytical study on biodiesel and diesel spray characteristics under ultra-high injection pressure. International Journal of Heat and Fluid Flow. 2010; 31:65966. https://doi.org/10.1016/j.ijheatfluidflow.2010.03.006

8. Kumar MLSD, Drakshayani S, Reddy KVK. Effect of fuel injection pressure on performance of single cylinder diesel engine at different intake manifold inclinations. International Journal of Engineering and Innovative Technology. 2012 Oct; 2(4).

9. Jing W, Roberts WL, Fang T. Effects of ambient temperature and oxygen concentration on diesel spray combustion using a single-nozzle injector in a constant volume combustion chamber. Combustion Science and Technology Journal. 2013; 185(9). https://doi.org/10.1080/00102202.2 013.798315

10. Akasyah MK, Mamat R, Abdullah A, Aziz A, Yassin HM. Effect of ambient temperature on dieselengine combustion characteristics operating with alcohol fuel. International Journal of Automotive and Mechanical Engineering. 2015 Jan-Jun; 11:2373-82. https://doi.org/10.15282/ijame.11.2015.18.0199

11. Reddy SSK, Pandurangadu V. Theoritical investigations of injection pressure in a four stroke di diesel engine with alcohol as fuel. International Journal of Mechanical Engineering and Technology. 2013; 4(2):209-16.

12. Khandal SV, Banapurmath NR, Gaitonde VN, Hiremath SS. Paradigm shift from mechanical direct injection diesel engines to advanced injection strategies of diesel Homogeneous Charge Compression Ignition (HCCI) engines-A comprehensive review. Renew Sustain Energy Rev. 2017; 70:369-84. https://doi.org/10.1016/j. rser.2016.11.058

13. Larsen PS, Bingham HB, Barker VA. Computational fluid dynamics, lecture notes for Course no. 41319. Technical University of Denmark; 2010. 
14. Swamy LR, Chandrashekar TK, Banapurmath NR, Nashipudi P. Effect of injection timing, combustion chamber shapes and nozzle geometry on the diesel engine performance. Universal Journal of Petroleum Sciences. 2014; 2(2014):74-95.

15. Benajes J, Olmeda P, Martín J, Blanco-Cavero D, Warey A. Evaluation of swirl effect on the global energy balance of a HSDI diesel engine. Energy. 2017; 122:168-81. https://doi.org/10.1016/j.energy.2017.01.082
16. Musa O, Xiong C, Changsheng Z, Li W. Effect of inlet conditions on swirling turbulent reacting flows in a solid fuel ramjet engine. Applied Thermal Engineering. 2017; 25(113):186207. https://doi.org/10.1016/j.applthermaleng.2016.11.023

17. ANSYS Workbench help, v18.

18. Tan Q, Hu Y, Zhang X, Zhang H. A study on the combustion performance of diesel engines with $\mathrm{O} 2$ and $\mathrm{CO} 2$ Suction. Journal of Chemistry. 2016; Volume 2016. https:// doi.org/10.1155/2016/1258314 